\title{
Bone Mineral Density and Secondary Hyperparathyroidism in Pulmonary Hypertension
}

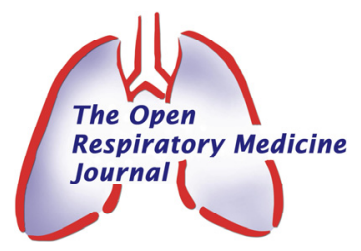

\author{
Silvia Ulrich*, Martin Hersberger, Manuel Fischler, Lars C. Huber, \\ Oliver Senn, Ursula Treder, Rudolf Speich and Christoph Schmid
}

\author{
Department of Internal Medicine, University Hospital of Zurich, Switzerland
}

\begin{abstract}
Background: Low bone mineral density (BMD) is common in chronic lung diseases and associated with reduced quality of life. Little is known about BMD in pulmonary hypertension (PH).

Methods: Steroid-naïve patients with PH ( $\mathrm{n}=34 ; 19$ idiopathic, 15 chronic thromboembolic) had BMD measured by DXA at the time of diagnostic right heart catheterization. Exercise capacity, quality of life and various parameters related to $\mathrm{PH}$ severity and bone metabolism were also assessed. 24 patients with left heart failure (LHF) were similarly assessed as controls.

Results: The prevalence of osteopenia was high both in PH (80\%) and in controls with LHF (75\%). Low BMD was associated with lean body mass, age, lower BMI, impaired exercise capacity and in PH with higher pulmonary vascular resistance. Serum parathyroid hormone (PTH) was elevated and considerably higher in PH than in LHF (above normal, in 55 vs 29\%). Secondary hyperparathyroidism was not related to impaired renal function but possibly to low vitamin D status.

Conclusions: Osteopenia is common in PH and in chronically ill patients with LHF. Osteopenia is associated with known risk factors but in $\mathrm{PH}$ also with disease severity. Preventive measures in an increasingly chronic ill $\mathrm{PH}$ population should be considered. Secondary hyperparathyroidism is highly prevalent in $\mathrm{PH}$ and might contribute to bone and possibly pulmonary vascular disease. Whether adequate vitamin D substitution could prevent low BMD in PH remains to be determined.
\end{abstract}

Keywords: Pulmonary hypertension, chronic thromboembolic pulmonary hypertension, hyperparathyroidism, osteopenia, osteoporosis, left heart failure.

\section{INTRODUCTION}

Low bone mineral density (BMD) is a common condition in patients with end-stage heart and lung disease independent of the underlying diagnosis $[1,2]$. While some of the risk factors such as low body mass index (BMI) are shared by most patients with severe pulmonary disease, others are more prevalent in specific lung diseases, such as history of smoking and systemic glucocorticoid use in chronic obstructive pulmonary disease and malnutrition in patients with cystic fibrosis $[1,2]$. Little attention has been paid to low $\mathrm{BMD}$ in patients with pulmonary hypertension $(\mathrm{PH}) . \mathrm{PH}$ represents a group of relatively rare disorders, whereby different pulmonary vascular alterations such as vasoconstriction, endothelial and smooth muscle cell proliferation, thrombosis and inflammation result in sustained elevated pulmonary vascular resistance and pulmonary arterial pressure $[3,4]$. Although PH is still an incurable disease, therapeutic advances in the last years have improved the life expectancy of patients [5-7]. Consequently, the management of clinical problems associated with chronic lung diseases such

*Address correspondence to this author at the Department of Internal Medicine, University Hospital of Zurich, Raemistrasse 100, 8091 Zurich, Switzerland; Tel: (+41) 4425541 62, (+41) 7862851 68; Fax: (+41) 4425585 19; E-mail: ulris@bluewin.ch as low BMD has become increasingly important in the care of PH-patients. Osteopenia has been found in nearly $60 \%$ of patients with idiopathic pulmonary arterial hypertension (IPAH) awaiting lung transplantation $[2,8]$. Consistent with general population studies and the known impact of muscle mass and physical activity on BMD [9-11], a positive correlation of both the body mass index (BMI, to some extent reflecting muscle mass) and the walking distance with the BMD was documented in some studies of patients with IPAH awaiting transplantation [2, 8, 12]. The pathogenetic mechanisms leading to decreased bone mass in end-stage $\mathrm{PH}$ are not known. Apart from general risk factors such as BMI and exercise capacity, other factors such as secondary hyperparathyroidism or disturbed vitamin $\mathrm{D}$ metabolism due to cardiac cirrhosis or a genetic background may play a role. Germline mutations in the bone morphogenetic protein receptor II (BMPR-II) gene (BMPR-2) have been described in familial and sporadic forms of $\mathrm{PH}$ [13-15]. Individual BMPs are key regulators of organogenesis [16], and were originally discovered based on their property to induce bone formation. Therefore, a contribution of the BMP signalling pathways to the pathogenesis of both pulmonary arterial vessel and bone disease could be hypothesized. However, the known clinical phenotype resulting from impaired BMPR-2 signalling is IPAH whereas an impact on the turnover of bone tissue has 
not been found thus far. Considering that $\mathrm{PH}$ resulting from thromboembolic disease (CTEPH) occurs in patients with a comorbid and genetic background distinct from that in IPAH, the aim of the present study was to investigate the prevalence of osteoporosis/osteopenia in patients with $\mathrm{PH}$ in general and according to classification and to look for correlations of the BMD with pulmonary haemodynamics, demographics, exercise performance, quality of life (QoL) and parameters related to calcium metabolism, bone turnover and disease severity. Since we aimed to see whether changes in bone and calcium metabolism in $\mathrm{PH}$ patients are unique or merely related to impaired exercise capacity with loss of muscle mass, we compared the prevalence of osteoporosis/osteopenia between $\mathrm{PH}$ and similarly exercise-limited patients with left heart failure (LHF).

\section{MATERIAL AND METHODOLOGY}

\section{Subjects}

Consecutive patients with IPAH or CTEPH seen at our $\mathrm{PH}$ clinic were prospectively included upon written informed consent. PH was defined as mean pulmonary arterial pressure $(\mathrm{mPAP}) \geq 25 \mathrm{mmHg}$ with a pulmonary capillary occlusion pressure $(\mathrm{PCOP}) \leq 15 \mathrm{mmHg}$ by right heart catheterisation. IPAH was diagnosed if a thorough evaluation by medical history, echocardiography, rheumatologic examination, antibody screening and additional tests according to best clinical practice did not reveal any other causes for the elevated pulmonary pressure [4]. CTEPH was diagnosed by both, radioisotope ventilation-perfusion scan and pulmonary angiography [17]. All patients had all investigations within two months of their heart catheter and had a 6 minute walk distance (6MWD) between 150 and 500 meters. Control patients with LHF with a similar 6MWD between 150-500 meters were recruited upon written informed consent from our heart centre. The controls were investigated similarly except for haemodynamics by catheter. The study was approved by our ethics committee.

\section{Demographics, History, Exercise Performance and Qual- ity of Life}

Patient's demographics (age, sex, height, weight and calculated body mass index [BMI in $\left.\mathrm{kg} / \mathrm{m}^{2}\right]$ ), history and lifestyle with emphasis on nutrition, calcium intake, smoking, drug use and history of bone fractures were assessed. Patients taking corticosteroids were excluded. NYHA functional class, 6MWD and Borg dyspnoea scale score were assessed. Quality of life (QoL) was assessed by the Minnesota living with hearth failure questionnaire [18].

\section{Osteoporosis Work-Up}

BMD was measured by dual-energy X-ray absorptiometry (DXA) with the QDR 4500 A (Hologic Inc, Waltham, MA) according to standard protocol at three sites: total proximal hip area (hip), the non-dominant femoral neck (FN) and the lumbar spine (LS). DXA images at the lumbar spine were reviewed by the same two experienced technicians (experience of 8 and 11 years) and vertebral bodies affected by degenerative changes were excluded from the analysis. The results were expressed in grams per square centimetre $\left(\mathrm{g} / \mathrm{cm}^{2}\right)$ and in $\mathrm{T}$-scores (numbers of standard deviations below the peak bone mass for an ethnically comparable ageand gender-matched reference population, as provided by the manufacturer). Osteoporosis and osteopenia were defined according to WHO (T-Sore $\leq-2.5$ respectively -1.0 to -2.5 ). In agreement with the International Society for Clinical Densitometry (ISCD) guidelines, the lowest measured value in either spine or hip was considered. Whole body composition (LBM, fat and bones) was measured during the same procedure. Chest X-rays were screened for vertebral fractures of the thoracic spine.

\section{Analysis in Blood and Urine}

Calcium, phosphate, creatinine, uric acid, bone-specific alkaline phosphatase (ostase $\AA$ ), albumin, bilirubin, total testosterone (men), estradiol (amenorrhoic women) and NTpro brain natriuretic peptide (NT-pro-BNP) were determined (Roche; Rotkreuz; Switzerland). Intact parathyroid hormone (PTH) and C-reactive protein by sensitive method (CRPsens) were measured (Immulite 2000; DPC; Los Angeles; USA). 25-hydroxyvitamin D was measured by radioimmunoassay (DiaSorin; Saluggia; Italy). Albumin-adjusted serum calcium was obtained as: calcium (mmol/l)-0.02*[albumin $(\mathrm{g} / \mathrm{l})-40]$. The glomerular filtration rate was calculated by using the corrected MDRD formula [19]. Whole blood was automatically analyzed for erythrocyte, leukocyte and thrombocyte counts. Urinary deoxypyridinoline (Immulite 2000; DPC; Los Angeles; USA) and calcium were analyzed in a second morning urine and expressed relative to urinary creatinine.

\section{Statistical Analysis}

Results are expressed as mean \pm standard deviations. The Mann Whitney-U test was used to compare means between groups (IPAH and CTEPH such as PH and LHF). Pearson's product moment correlation and Spearman's rho were used to correlate BMD and T-scores with demographics, pulmonary haemodynamics, exercise performance and QoL and laboratory values. Multiple linear regression was used to study associations between the diagnosis $\mathrm{PH}$ and $\mathrm{BMD} / \mathrm{BMC}$ and PTH corrected for possible confounders (age, sex, BMI, creatinine clearance, serum levels of calcium, phosphate and vitamin D). Outcome-parameters were normalized using log-transformation. Differences showing $\mathrm{p}$ values $<0.05$ were considered statistically significant.

\section{RESULTS}

\section{Patient's Characteristics}

PH-study group: We included 19 patients (13 females) with IPAH (age $64 \pm 15$ years) and 15 patients ( 9 females) with CTEPH (age 65 \pm 12 years) in the study (Table 1). Most patients were in NYHA class III and IV. IPAH patients had a significantly lower 6MWD $(342 \pm 87 \mathrm{~m})$ compared with CTEPH (424 $\pm 62 \mathrm{~m}, \mathrm{p}=0.004)$ with a similar Borg dyspnoea scale and decline in oxygen saturation during the test. The mean mPAP, CI and PVR were comparable between IPAH and CTEPH (Table 1).

Control group with LHF: 24 patients (9 females), age $67 \pm 12$ with left heart disease ( $7=$ valvular, $8=$ ischemic, $9=$ myocardial) were included as controls. Most of them were in NYHA class III and IV (Table 1) and walked slightly less than PH-patients (6MWD 288 $\pm 92 \mathrm{~m}, \mathrm{p}<0.001$ ). The total 
Table 1. Characteristics of PH-Patients and Controls

\begin{tabular}{|c|c|c|c|c|c|}
\hline & $\begin{array}{l}\text { IPAH } \\
(n=19)\end{array}$ & $\begin{array}{c}\text { CTEPH } \\
(n=15)\end{array}$ & $\begin{array}{c}\text { LHF-Controls } \\
(\mathbf{n}=\mathbf{2 4})\end{array}$ & $\begin{array}{c}\text { PAH vs CTEPH } \\
\text { (p-Values) }\end{array}$ & $\begin{array}{r}\text { PH vs LHF } \\
\text { (p-Values) }\end{array}$ \\
\hline \multicolumn{6}{|l|}{ General } \\
\hline Sex (females/males) & $13 / 6$ & $9 / 6$ & $9 / 15$ & 0.724 & 0.061 \\
\hline Age (years) & $64(15)$ & $65(12)$ & $67(12)$ & 0.891 & 0.543 \\
\hline NYHA functional class (II / III / IV) & $1 / 9 / 9$ & $1 / 10 / 4$ & $1 / 10 / 13$ & 0.102 & 0.655 \\
\hline 6 minute walk distance $(\mathrm{m})$ & $342(87)$ & $424(62)$ & $288(93)$ & $0.004 *$ & $<0.001 * *$ \\
\hline QoL total (points) & $44(3)$ & $37(17)$ & $42(21)$ & 0.226 & 0.766 \\
\hline QoL physical subscore (points) & $24(7)$ & $21(5)$ & $24(10)$ & 0.062 & 0.258 \\
\hline QoL emotional subscore (points) & $9(6)$ & $9(7)$ & $6(7)$ & 0.890 & $0.027 *$ \\
\hline \multicolumn{6}{|l|}{ Pulmonary Haemodynamics* } \\
\hline Mean pulmonary arterial pressure $(\mathrm{mm} \mathrm{Hg})$ & $48(11)$ & $42(10)$ & & 0.199 & \\
\hline Pulmonary vascular resistance (dyne* $\left.\mathrm{s}^{*} \mathrm{~cm}^{5}\right)$ & $760(408)$ & $724(298)$ & & 0.953 & \\
\hline Cardiac Index $\left(1 / \mathrm{min} / \mathrm{m}^{2}\right)$ & $2.2(0.2)$ & $2.0(0.5)$ & & 0.529 & \\
\hline Mixed venous oxygen saturation (\%) & $58(10)$ & $54(8)$ & & 0.132 & \\
\hline Arterial oxygen saturation (\%) & $90(5)$ & $88(4)$ & & 0.065 & \\
\hline
\end{tabular}

$* \mathrm{p}<0.05, * * \mathrm{p}<0.001$.

Data are given as numbers or means (SD)

QoL and its physical subscore were comparable between PH and LHF, but the emotional subscore was lower in LHF controls.

None of the patients reported a history of bone fracture and all patients had a minimum calcium intake of $\geq 1000 \mathrm{mg}$. Chest $\mathrm{x}$-ray analysis revealed asymptomatic vertebral fractures in two women with $\mathrm{PH}(6 \%)$ and one man with LHF (4\%). PH specific drugs used in IPAH and CTEPH were inhaled iloprost (16 and 20\%), bosentan (63 and 66\%) and sildenafil (42 and 33\%). Other drugs reported in IPAH, CTEPH and LHF included loop diuretics $(58,87,79 \%)$, thiazides $(10,7,12 \%)$, phenprocoumon $(100,100,50 \%)$, low dose aspirin $(5,13,32 \%)$, angiotensin converting enzyme inhibitors and/or angiotensin receptor blockers $(26,27,92$ $\%$, beta-blockers $(16,7,58 \%)$, calcium-channel blockers $(32,27,13 \%)$, nitrates $(5,7,17 \%)$, statins $(21,20,37.5 \%)$, proton-pump-inhibitors $(26,33,17 \%)$, serotonin-reuptakeinhibitors $(16,7 \%, 8 \%)$.

\section{Prevalence of Osteoporosis and Osteopenia}

About half of the patients with PH had osteopenia and one quarter had osteoporosis, with no significant difference between IPAH and CTEPH (Fig. 1, Table 2). The overall prevalence of osteoporosis/osteopenia was similar in the LHF controls but the mean BMD and T-scores tended to be lower in $\mathrm{PH}$, especially at the hip ( $\mathrm{p}=\mathrm{ns}$, Fig. 1, Table 2). The total bone mineral content (BMC) was lower in both PH-groups compared to LHF ( $p=0.052)$. LBM and fat were comparable in PH and LHF (Table 2).

\section{Analysis in Blood and Urine}

General parameters: Mean pro-BNP levels were markedly elevated without any difference between groups (Table 3). Mean CRPsens was significantly higher in LHF compared with $\mathrm{PH}(\mathrm{p}=0.007)$. Mean total protein and albumin levels were lower in LHF than in $\mathrm{PH}(\mathrm{p}<0.001$, Table 3$)$. Mean uric acid levels were above the normal limit without difference between groups. Parameters reflecting kidney function were slightly impaired in all groups.

Parameters related to bone metabolism: Serum calcium, phosphate and sex hormone levels were within normal limits in all groups. Phosphate was higher in LHF $(p=0.009)$, whereas serum PTH, ostase and urinary calcium were higher in $\mathrm{PH}(\mathrm{p}=0.027,0.002,0.031) .25$-hydroxyvitamin $\mathrm{D}$ levels were $<10 \mu \mathrm{g} / 1$ in $21 \%$ of the patients with PH and in $8 \%$ of LHF-controls. PTH levels were above the reference range in $55 \%$ of patients with PH (IPAH 47\%, CTEPH 67\%) and $29 \%$ of LHF (Fig. 2, $\mathrm{p}=0.044$ ). Mean PTH serum levels and urinary calcium excretion did not differ between patients taking or not taking loop diuretics. Urinary deoxypyridinoline excretion was equally elevated in both, $\mathrm{PH}$ and LHF patients.

\section{Correlations of BMD with Clinical Parameters in PH}

With sex: The BMD (total, $\mathrm{g} / \mathrm{cm}^{2}$ and T-scores) measured at the hip was significantly lower in females than in males $(\mathrm{p}<0.001)$.

With age: We found a significant negative correlation between age and BMD $\left(\mathrm{g} / \mathrm{cm}^{2}\right.$ and T-scores) measured at the $\mathrm{FN}(\mathrm{r}=-0.315$ and $-0.29 ; \mathrm{p}=0.009$ and 0.016$)$. 


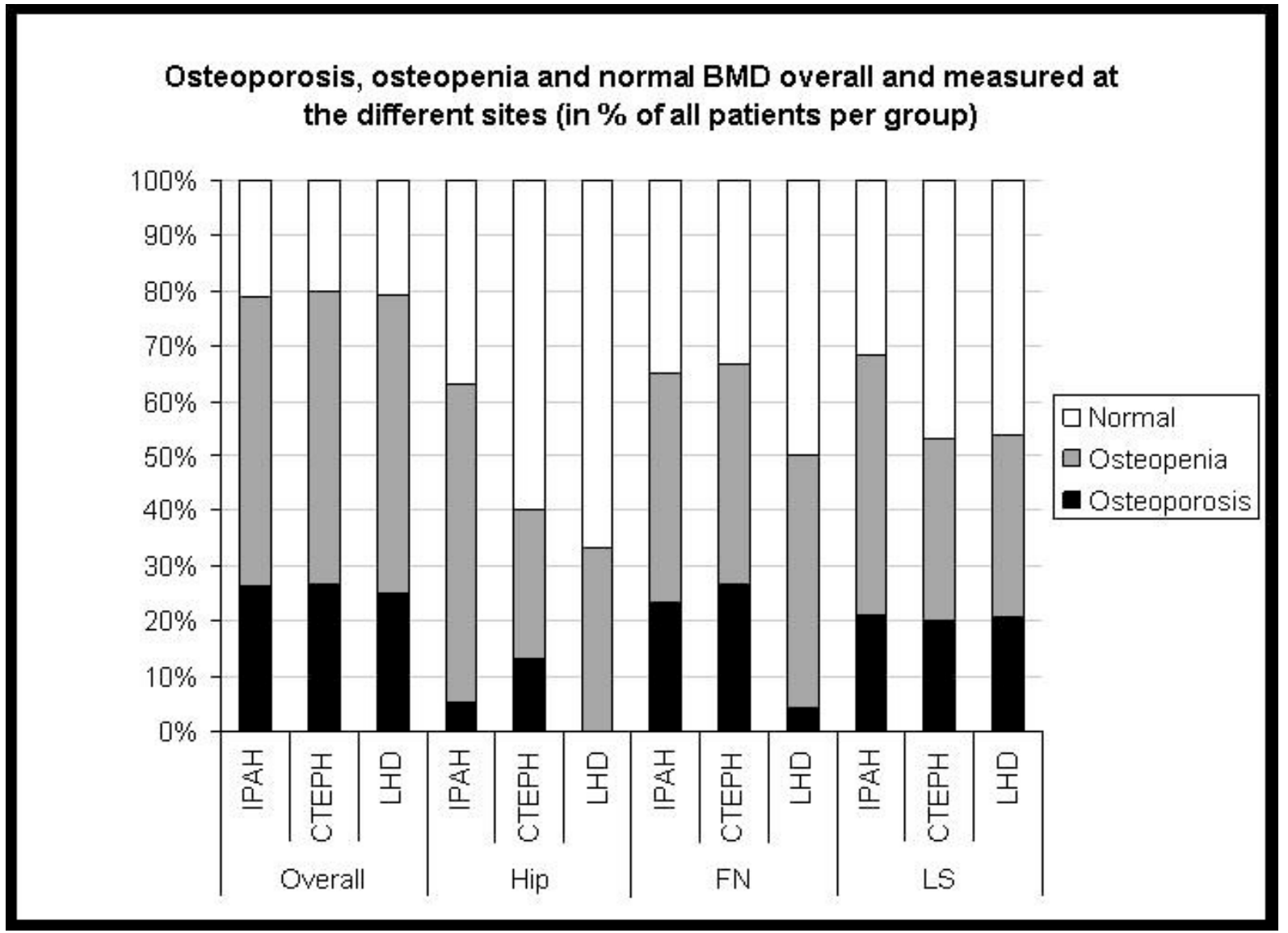

Fig. (1). Proportion of patients with osteoporosis, osteopenia and normal BMD. BMD = bone mineral density, IPAH = idiopathic pulmonary arterial hypertension. $\mathrm{CTEPH}=$ chronic thromboembolic pulmonary hypertension, $\mathrm{LHF}=$ left heart disease, $\mathrm{FN}=\mathrm{femoral}$ neck, $\mathrm{LS}=$ lumbar spine.

With body composition: BMI and LBM positively correlated with T-scores at the hip and FN.

With pulmonary haemodynamics: PVR negatively correlated with BMD measured at the hip $(r=-0.254$ resp -0.267 ; $\mathrm{p}=0.039$ and 0.03 for $\mathrm{g} / \mathrm{cm}^{2}$ and $\mathrm{T}$-scores) and LS $(\mathrm{r}=-0.305$ and $-0.300 ; p=0.013$ resp 0.014 ).

With exercise performance and QoL: We found a positive correlation of the 6MWD with the BMD only in CTEPH at the hip $(\mathrm{r}=0.308, \mathrm{p}=0.034)$.
With different clinical chemistry parameters: We found a weak positive correlation of LS-BMD $\left(\mathrm{g} / \mathrm{cm}^{2}\right.$ and T-scores) with serum creatinine $(\mathrm{r}=0.24$ resp $0.23 ; \mathrm{p}=0.049$ resp 0.05$)$ and a negative correlation with ostase $(\mathrm{r}=-0.243$ resp -0.283 ; $\mathrm{p}=0.048$ resp 0.02).

Multivariate analysis: In a multiple linear regression model including age, sex, BMI and the serum levels of calcium, phosphate and PTH as co-factors we found a trend towards lower BMD and BMC for patients with $\mathrm{PH}$ compared to $\mathrm{LHF}$ ( $\mathrm{PH}$ around $2.5 \%, \mathrm{p}=\mathrm{ns}$ ).

Table 2. BMD and Body Composition Results by DXA

\begin{tabular}{|c|c|c|c|c|c|}
\hline & IPAH (n=19) & CTEPH (n=15) & LHF-Controls (n=24) & PAH vs CTEPH (p-Values) & PH vs LHF (p-Values) \\
\hline \hline Osteoporosis / Osteopenia (n, \%) & $5 / 10(26 / 53)$ & $4 / 8(27 / 53)$ & $6 / 12(25 / 50)$ & $-0.62(0.87)$ & 0.656 \\
\hline T-score hip & $-1.03(1.09)$ & $-0.95(1.23)$ & $-0.91(0.886)$ & 0.655 & 0.973 \\
\hline T-score FN & $-1.34(1.16)$ & $-1.39(1.16)$ & $-1.03(1.62)$ & 0.391 & 0.092 \\
\hline T-score LS & $-1.20(1.70)$ & $-1.23(1.61)$ & $2.94(2.7)$ & 0.973 & 0.052 \\
\hline Total body bone mineral content (kg) & $2.06(4.8)$ & $2.26(5.6)$ & $51.8(12.8)$ & 0.811 \\
\hline Lean body mass (kg) & $48.0(6.4)$ & $48.5(8.9)$ & $25.4(11.7)$ & 0.151 \\
\hline \multicolumn{2}{|c|}{ Fat (kg) } & $22.6(9.9)$ & $21.1(7.7)$ & & 0.377 \\
\hline
\end{tabular}


Table 3. Blood and Urine Analysis

\begin{tabular}{|c|c|c|c|c|c|}
\hline \multicolumn{6}{|l|}{ General } \\
\hline pro-BNP $(<88$ ng/L) & $2500(1874)$ & $2256(1505)$ & $3617(3501)$ & 0.97 & 0.224 \\
\hline C-reactive protein $(<1 \mathrm{mg} / \mathrm{l})$ & $9.2(9.5)$ & $10.4(10.4)$ & $16.9(13.6)$ & 0.957 & $0.007^{*}$ \\
\hline Creatinine $(\mathrm{Cr})(44-80 \mu \mathrm{mol} / \mathrm{L})$ & $110(38)$ & $95(9)$ & $114(33)$ & 0.228 & 0.209 \\
\hline $\operatorname{GFR} \operatorname{MDRD}\left(>60 \mathrm{ml} / \mathrm{min} / \mathrm{m}^{2}\right)^{* * *}$ & $47(16)$ & $51(11)$ & $47(13)$ & 0.376 & 0.764 \\
\hline Albumin (34-48 g/l) & $44(10)$ & $42(4)$ & $38(3)$ & 0.631 & $<0.001^{* *}$ \\
\hline Phosphate $(0.87-1.45 \mathrm{mmol} / \mathrm{L})$ & $0.99(0.2)$ & $1.02(0.2)$ & $1.21(0.3)$ & 0.246 & $0.009 *$ \\
\hline Ostase $(3.4-9.8 \mu \mathrm{g} / \mathrm{L})$ & $15.3(6)$ & $14.9(6)$ & $10.7(6)$ & 0.800 & $0.002 *$ \\
\hline PTH (15-65 ng/L) & $88(71)$ & $93(45)$ & $56(23)$ & 0.331 & $0.027 *$ \\
\hline 25-Hydroxy-Vitamin D (10-42 $\mu \mathrm{g} / \mathrm{L})$ & $15(6)$ & $15(8)$ & $19(10)$ & 0.556 & 0.137 \\
\hline Urinary calcium/creatinine ( $0.1-0.5 \mathrm{mmol} / \mathrm{mmol})$ & $0.47(0.42)$ & $0.62(0.64)$ & $0.30(0.31)$ & 0.794 & $0.031 *$ \\
\hline Urinary deoxypyridinoline/creatinine $(2.5-5 \mathrm{nmol} / \mathrm{mmol})$ & $7.87(10.3)$ & $7.63(1.98)$ & $8.64(4.12)$ & 0.710 & 0.676 \\
\hline
\end{tabular}

Normal values in brackets after parameters. Results given as means (SD).

$* \mathrm{p}<0.05, * * \mathrm{p}<0.00$. $* * *$ Albumin-adjusted serum calcium $=$ calcium $(\mathrm{mmol} / \mathrm{l})-0.02 *[\operatorname{albumin}(\mathrm{g} / \mathrm{l})-40]$

$* * * *$ GFR (MDRD) $\left[\mathrm{ml} / \mathrm{min} / 1.73 \mathrm{~m}^{2}\right]=186^{*}(\text { serum } \mathrm{Cr}(\mathrm{mg} / \mathrm{dl}) / 0.95)^{-1.154 *}(\text { age })^{-0.203 *}(0.742$ in women $)$.

\section{Correlations of PTH with Clinical Parameters in PH}

PTH correlated positively with ostase ( $\mathrm{r}=0.301$; $\mathrm{p}=0.017)$, albumin $(\mathrm{r}=0.343 ; \mathrm{p}=0.008)$, uric acid $(\mathrm{r}=0.258$; $\mathrm{p}=0.038)$, the CI $(\mathrm{r}=0.279 ; \mathrm{p}=0.027)$ and the PCOP $(\mathrm{r}=0.262$; $\mathrm{p}=0.04)$ and negatively with $25-\mathrm{OH}-\mathrm{vitamin} \mathrm{D}(\mathrm{r}=-0.314$, $\mathrm{p}=0.011$ ).

Multivariate analysis: In a multiple linear regression model including age, sex, BMI, glomerular filtration rate and serum levels of calcium, phosphate and vitamin D as possible confounders we still found that the diagnosis of $\mathrm{PH}$ was associated with higher PTH serum levels $(\mathrm{p}=0.05)$.

\section{DISCUSSION}

In the present study we found a high prevalence of osteoporosis/osteopenia in $\mathrm{PH}$, but also in patients suffering from LHF. A T-score of $<-1.0$ was present in approximately $80 \%$ of the patients, without any difference between the IPAH and CTEPH. Higher age, female gender, low body weight, sex hormone deficiency, sedentary life style, decreased calcium intake and extended corticosteroid use are accepted risk factors for osteopenia in the general population [11]. Osteopenia affects not only the elderly but also patients suffering from gastrointestinal, liver and kidney diseases [20-23]. As for lung diseases, an association with low BMD has been found in COPD, cystic fibrosis and other end stage diseases $[2,8,24,25]$. Our finding of a high incidence of osteopenia in PH-patients might have important clinical implications.

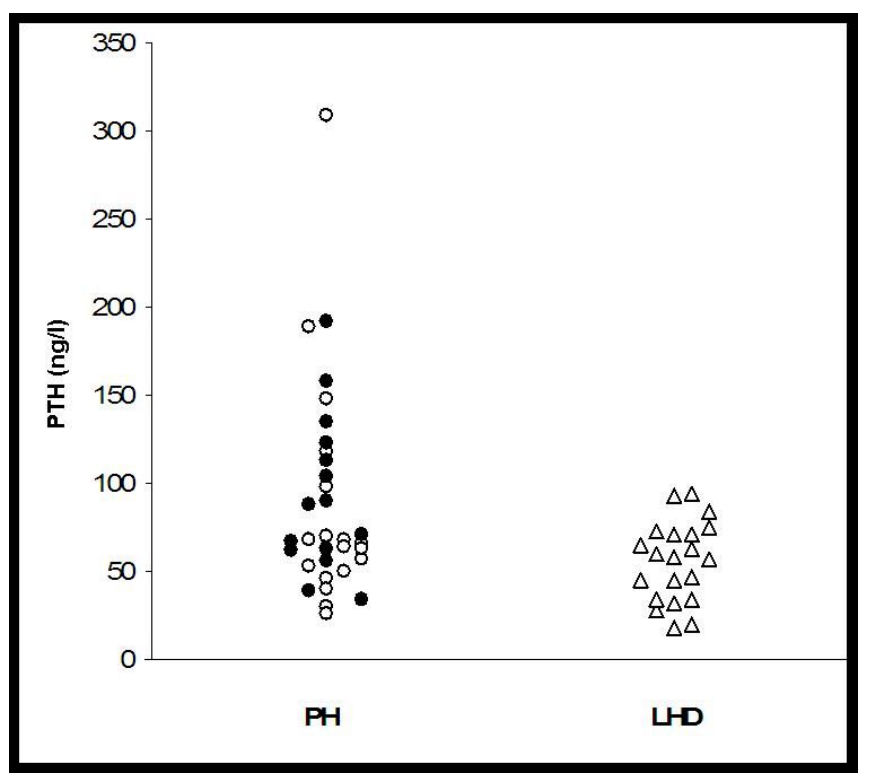

Fig. (2). Parathyroid hormone levels in patients with PH and LHF. $\mathrm{PH}=$ pulmonary hypertension, $\mathrm{PTH}=$ parathyroid hormone, LHF $=$ left heart disease. Open circles, idiopathic pulmonary arterial hypertension (IPAH), closed circles chronic thromboembolic pulmonary hypertension (CTEPH).

Low BMD is associated with increased morbidity and reduced quality of life [26]. Interestingly, our patients did not reported bone fractures despite the low BMD and only $6 \%$ 
revealed vertebral fractures in their chest x-ray. It might be that the relatively young age and exercise limitation due to $\mathrm{PH}$ reduced the risk for falls in this population. Consistent with other studies performed in patients with heart disease [27], we also found a high prevalence of low BMD in comparably exercise-limited patients with LHF (Table 2).

In line with previous studies, we found only a weak association between higher age and female gender with low $\mathrm{BMD}$, and we confirm the particularly strong association between BMI and BMD [2]. We now extend these findings by showing an even more striking association with LBM, presumably even better reflecting muscle mass than BMI. By contrast, the 6MWD was less clearly related to BMD, possibly as this test estimates the actual exercise capacity and does not the reflect the exercise capacity over time.

Interestingly, we found a negative correlation of the BMD with the PVR. The present results of a negative correlation of BMD and PVR are consistent with our previous retrospective analysis of PH-patients awaiting lung transplantation and demonstrate for the first time an association between pulmonary haemodynamics and BMD in a prospective study. Furthermore, a multivariate model corrected for common confounders showed a trend towards an association between the diagnosis of PH and lower BMC. For ethical concerns we did not have pulmonary hemodynamics by right heart catheterisation available in controls with LHF which is indeed a limitation of our study since we cannot rule out that some of the LHF controls could have elevated pulmonary artery pressures due to backpressure from pulmonary venous hypertension. Furthermore, our cross-sectional study could not fully estimate the impacts of disease severity and duration on BMD. Speculating about potential underlying pathogenetic mechanisms, genetic mutations could favour the development of both PH and low BMD. However, the even stronger negative correlation of BMD with PVR in CTEPH patients compared with IPAH discourages the hypothesis of specific genetics contributing to both low BMD and increased pulmonary artery pressure and rather suggests a relation between the disease severity with possible associated metabolic changes and low BMD. Another link between bone and $\mathrm{PH}$ might be the serotonin system which plays a pathogenetic role in various forms of $\mathrm{PH}$ [3] and more recently has been reported to regulate bone mass [28]. Such potential pathogenetic links are certainly worth of further research.

Interestingly, we found a particularly striking elevation of the mean PTH serum levels in patients with PH (Table 3). An increased PTH was found in more than half of all PH patients (Fig. 2). PH seems to be a predictor of high PTH serum levels even in a multivariate model corrected for age, sex, BMI, serum calcium, phosphate and vitamin D levels. Elevated serum PTH levels have been described in patients with severe congestive LHF, and serum PTH has been shown to be a predictor of cardiovascular mortality in an elderly population, irrespective of the vitamin D status [27, $29,30]$. Usually, elevated PTH in heart failure patients has been attributed to secondary hyperparathyroidism due to impaired renal function and/or induction by loop diuretics (due to hypercalciuria) [31]. However, hyperparathyroidism has also been demonstrated in LHF patients who did not receive loop diuretics [32].
Regarding our PH patients, 70\% (and 79\% LHF) were treated with loop diuretics; we found no difference in mean PTH serum levels between loop diuretic-treated and not treated individuals in any group and also no relation to impaired renal function. It thus appears that neither increased creatinine nor diuretics account for high PTH levels, and that factors other than renal failure or drugs, possibly vitamin D deficiency, endothelial dysfunction or altered haemodynamics, might be responsible for secondary hyperparathyroidism in PH. Serum levels of PTH have not only been described to be elevated in congestive heart failure, but also in a broad spectrum of critically ill patients in the emergency department and have been shown to be related to disease severity and mortality [33]. Kidney disease is a classical cause of secondary hyperparathyroidism. In patients with chronic renal failure, values of PAP correlated directly with serum levels of PTH $[34,35]$. Interestingly, PTH serum levels in PH correlated with the PCOP. The PCOP is the key hemodynamic parameter to distinguish pulmonary arterial hypertension from pulmonary venous hypertension as often seen in LHF. It therefore would have been of interest to know, if the PCOP would have correlated with PTH levels in LHFcontrols as well. Unfortunately, this hemodynamic data in the LHF-group is lacking and it remains unclear whether the relatively lower PTH levels in LHF in this study are associated with less elevated PCOP in this group. We found no significant correlation of the PTH with the pulmonary artery pressure or vascular resistance. Our finding of significantly increased serum PTH levels in patients with right heart failure merits attention; it may reflect a vascular problem or point towards a hormonal role of PTH in the vasculature. Secondary hyperparathyroidism, FN osteoporosis and hip fractures have been considered characteristic of osteoporosis in elderly patients [36]. In our PH patients, increased PTH correlated positively with bone-specific alkaline phosphatase and negatively with 25 -hydroxyvitamin D levels. Therefore, inappropriate vitamin D status may contribute to both sarcopenia and secondary hyperparathyroidism in PH. Indeed, the 25-OH vitamin D levels in our cohort, although within the reference range in most of the patients, were low. We have no actual reasonably (age-, sex- and referral pattern-) matched reference cohort available; however, it is noteworthy that the mean $25-\mathrm{OH}$ vitamin D levels in our PH patients were almost identical to those found in elderly (age 65+, mean $>80$ years) patients admitted from home (from a comparable referral area, over the same time period, assessed with the same $25-\mathrm{OH}$ vitamin D assay) to the hospital for hip fracture, considered severely vitamin D deficient [37]. It may well be that the high prevalence of low vitamin D levels found in PH contributes to secondary hyperparathyroidism.

\section{CONCLUSION}

In summary, this cross-sectional study shows that low BMD is fairly common in both, IPAH and CTEPH, but also LHF. Increased awareness of osteopenia in PH might be important in order to prevent fractures and save QoL. The finding of increased serum levels of PTH in PH is novel and merits attention. Secondary hyperparathyroidism in our $\mathrm{PH}$ population was not associated to impaired renal function but possibly to inappropriate vitamin $\mathrm{D}$ status. Whether adequate vitamin D substitution may prevent secondary hyperparathyroidism and low BMD in PH remains to be determined. 


\section{ABBREVIATIONS}

\begin{tabular}{|c|c|c|}
\hline $\mathrm{BMC}$ & $=$ & Bone mineral content \\
\hline BMD & $=$ & Bone mineral density \\
\hline BMI & $=$ & Body mass index \\
\hline BMPR & $=$ & Bone morphogenetic protein receptor \\
\hline $\mathrm{BNP}$ & $=$ & Brain natriuretic peptide \\
\hline BSA & $=$ & Body surface area \\
\hline CI & $=$ & Cardiac index \\
\hline COPD & $=$ & Chronic obstructive pulmonary disease \\
\hline CRP & $=$ & C-reactive protein \\
\hline CTEPH & $=$ & $\begin{array}{l}\text { Chronic thromboembolic pulmonary } \\
\text { hypertension }\end{array}$ \\
\hline $\mathrm{FN}$ & $=$ & Femoral neck \\
\hline IPAH & $=$ & Idiopathic pulmonary arterial hypertension \\
\hline LBM & $=$ & Lean body mass \\
\hline LHF & $=$ & Left heart disease \\
\hline LS & $=$ & Lumbar spine \\
\hline mPAP & $=$ & Mean pulmonary arterial pressure \\
\hline $\mathrm{N}$ & $=$ & Normal value \\
\hline NYHA & $=$ & New York Heart Association \\
\hline PCOP & $=$ & Pulmonary capillary occlusion pressure \\
\hline PVR & $=$ & Pulmonary vascular resistance \\
\hline PH & $=$ & Pulmonary hypertension \\
\hline PTH & $=$ & Parathyroid hormone \\
\hline QoL & $=$ & Quality of Life \\
\hline TGF & $=$ & Transforming growth factor \\
\hline 5MWD & $=$ & 6 minute walk distance \\
\hline
\end{tabular}

\section{ACKNOWLEDGEMENTS}

We thank the Velux Foundation, Binzstrasse 18, 8045 Zurich, Switzerland, for financial support of the study.

\section{CONFLICT OF INTEREST}

None of the authors has any conflict of interest with the present work.

\section{REFERENCES}

[1] Shane E, Silverberg SJ, Donovan D, et al. Osteoporosis in lung transplantation candidates with end-stage pulmonary disease. Am J Med 1996; 101: 262-9.

[2] Tschopp O, Boehler A, Speich R, et al. Osteoporosis before lung transplantation: association with low body mass index, but not with underlying disease. Am J Transplant 2002; 2: 167-72.

[3] Humbert M, Morrell NW, Archer SL, et al. Cellular and molecular pathobiology of pulmonary arterial hypertension. J Am Coll Cardiol 2004; 43: 13S-24S.

[4] Simonneau G, Galie N, Rubin LJ, et al. Clinical classification of pulmonary hypertension. J Am Coll Cardiol 2004; 43: 5S-12S.

[5] Badesch DB, McLaughlin VV, Delcroix M, et al. Prostanoid therapy for pulmonary arterial hypertension. J Am Coll Cardiol 2004; 43: 56S-61S.
[6] McLaughlin VV, Sitbon O, Badesch DB, et al. Survival with firstline bosentan in patients with primary pulmonary hypertension. Eur Respir J 2005; 25: 244-9.

[7] Badesch DB, Abman SH, Ahearn GS, et al. Medical therapy for pulmonary arterial hypertension: ACCP evidence-based clinical practice guidelines. Chest 2004; 126: 35S-62S.

[8] Tschopp O, Schmid C, Speich R, et al. Pretransplantation bone disease in patients with primary pulmonary hypertension. Chest 2006; 129: 1002-8.

[9] Krall EA, Dawson-Hughes B. Walking is related to bone density and rates of bone loss. Am J Med 1994; 96: 20-6.

[10] Gregg EW, Cauley JA, Seeley DG, et al. Physical activity and osteoporotic fracture risk in older women. Study of Osteoporotic Fractures Research Group. Ann Int Med 1998; 129: 81-8.

[11] Felson DT, Zhang Y, Hannan MT, et al. Effects of weight and body mass index on bone mineral density in men and women: the Framingham study. J Bone Miner Res 1993; 8: 567-73.

[12] Aris RM, Neuringer IP, Weiner MA, et al. Severe osteoporosis before and after lung transplantation. Chest 1996; 109: 1176-83.

[13] Humbert M, Trembath RC. Genetics of pulmonary hypertension: from bench to bedside. Eur Respir J 2002; 20: 741-9.

[14] Morse JH, Deng Z, Knowles JA. Genetic aspects of pulmonary arterial hypertension. Ann Med 2001; 33: 596-603.

[15] Morse JH. Bone morphogenetic protein receptor 2 mutations in pulmonary hypertension. Chest 2002; 121: 50S-53S.

[16] Wozney JM, Rosen V. Bone morphogenetic protein and bone morphogenetic protein gene family in bone formation and repair. Clin Orthop 1998: 26-37.

[17] Hoeper MM, Mayer E, Simonneau G, et al. Chronic thromboembolic pulmonary hypertension. Circulation 2006; 113: 2011-20.

[18] Cenedese E, Speich R, Dorschner L, et al. Measurement of quality of life in pulmonary hypertension and its significance. Eur Respir J 2006; 28: 808-15.

[19] Levey AS, Bosch JP, Lewis JB, et al. A more accurate method to estimate glomerular filtration rate from serum creatinine: a new prediction equation. Modification of Diet in Renal Disease Study Group. Ann Intern Med 1999; 130: 461-70.

[20] Robinson RF, Nahata MC. Prevention and treatment of osteoporosis in the cystic fibrosis population. J Pediatr Health Care 2001; 15 : 308-15.

[21] Cunningham J, Sprague SM, Cannata-Andia J, et al. Osteoporosis in chronic kidney disease. Am J Kidney Dis 2004; 43: 566-71.

[22] Roblin X, Bonaz B. Osteoporosis and inflammatory bowel disease. Am J Gastroenterol 2007; 102: 209; author reply 209-10.

[23] Sanchez AJ, Aranda-Michel J. Liver disease and osteoporosis. Nutr Clin Pract 2006; 21: 273-8.

[24] Conway S. Osteoporosis is cystic fibrosis. J Cyst Fibros 2003; 2: 161-2.

[25] Ionescu AA, Schoon E. Osteoporosis in chronic obstructive pulmonary disease. Eur Respir J Suppl 2003; 46: 64s-75s.

[26] Borgstrom F, Zethraeus N, Johnell O, et al. Costs and quality of life associated with osteoporosis-related fractures in Sweden. Osteoporos Int 2006; 17: 637-50.

[27] Shane E, Mancini D, Aaronson K, et al. Bone mass, vitamin D deficiency, and hyperparathyroidism in congestive heart failure. Am J Med 1997; 103: 197-207.

[28] Yadav VK, Ryu JH, Suda N, et al. Lrp5 controls bone formation by inhibiting serotonin synthesis in the duodenum. Cell 2008; 135: 825-37.

[29] Sambrook PN, Chen JS, March LM, et al. Serum parathyroid hormone is associated with increased mortality independent of 25hydroxy vitamin d status, bone mass, and renal function in the frail and very old: a cohort study. J Clin Endocrinol Metab 2004; 89: 5477-81.

[30] Bjorkman MP, Sorva AJ, Tilvis RS. Elevated serum parathyroid hormone predicts impaired survival prognosis in a general aged population. Eur J Endocrinol 2008; 158: 749-53.

[31] Rejnmark L, Vestergaard P, Heickendorff L, et al. Effects of longterm treatment with loop diuretics on bone mineral density, calcitropic hormones and bone turnover. J Intern Med 2005; 257: 17684.

[32] Khouzam RN, Dishmon DA, Farah V, et al. Secondary hyperparathyroidism in patients with untreated and treated congestive heart failure. Am J Med Sci 2006; 331: 30-4.

[33] Carlstedt F, Lind L, Wide L, et al. Serum levels of parathyroid hormone are related to the mortality and severity of illness in pa- 
tients in the emergency department. Eur J Clin Invest 1997; 27: 977-81.

[34] Kumbar L, Fein PA, Rafiq MA, et al. Pulmonary hypertension in peritoneal dialysis patients. Adv Perit Dial 2007; 23: 127-31.

[35] Nasri H. Pulmonary artery pressure in association with serum parathormone in maintenance hemodialysis patients. Arch Med Sci $2006 ; 2: 32-5$
[36]

Boonen S, Broos P, Verbeke G, et al. Calciotropic hormones and markers of bone remodeling in age-related (type II) femoral neck osteoporosis: alterations consistent with secondary hyperparathyroidism-induced bone resorption. J Gerontol A Biol Sci Med Sci 1997; 52: M286-93.

[37] Bischoff-Ferrari HA, Can U, Staehelin HB, et al. Severe vitamin D deficiency in Swiss hip fracture patients. Bone 2008; 42: 597-602.

Received: January 12, 2009

Revised: January 15, 2009

Accepted: January 23, 2009

(C) Ulrich et al.; Licensee Bentham Open.

This is an open access article licensed under the terms of the Creative Commons Attribution Non-Commercial License (http://creativecommons.org/licenses/by$\mathrm{nc} / 3.0 /$ ) which permits unrestricted, non-commercial use, distribution and reproduction in any medium, provided the work is properly cited. 